\author{
D. C. Henstridge $\cdot$ B. A. Kingwell $\cdot$ M. F. Formosa $\cdot$ \\ B. G. Drew - G. K. McConell · S. J. Duffy
}

\title{
Effects of the nitric oxide donor, sodium nitroprusside, on resting leg glucose uptake in patients with type 2 diabetes
}

Received: 19 June 2005 / Accepted: 22 August 2005 / Published online: 5 November 2005

(C) Springer-Verlag 2005

\begin{abstract}
Aims/hypothesis: Nitric oxide (NO) has been implicated as an important signalling molecule in the contraction-mediated glucose uptake pathway and may represent a novel strategy for blood glucose control. The current study sought to determine whether acute infusion of the NO donor, sodium nitroprusside (SNP), increases leg glucose uptake at rest in patients with type 2 diabetes. Methods: Fifteen male patients with type 2 diabetes (aged $54 \pm 4$ years, mean $\pm \mathrm{SD}$ ) were entered into a randomised, cross-over design study, examining the effect of a 30-min intra-femoral infusion of SNP on leg glucose uptake. Comparison was made with a 30-min infusion of verapamil, titrated to elicit similar leg blood flow responses to SNP. Leg blood flow was measured by thermodilution in the femoral vein, and leg glucose uptake was calculated as the product of leg blood flow and the femoral arterio-venous (A-V) glucose concentration gradient. Results: The two drugs increased leg blood flow to a similar extent ( $p=$ 0.50 ). Both leg $\mathrm{A}-\mathrm{V}$ glucose concentration gradient (SNP $0.12 \pm 0.05$, verapamil $-0.06 \pm 0.04 \mathrm{mmol} / \mathrm{l} ;$ mean $\pm \mathrm{SEM}$, $p=0.03$ ) and leg glucose uptake (SNP $0.17 \pm 0.09$, verapamil $-0.09 \pm 0.06 \mathrm{mmol} / \mathrm{min} ; p=0.03$ ) were higher with the SNP treatment than with verapamil. These results occurred independently of any significant difference in plasma insulin concentration between drugs $(p=0.56)$. Conclusions/interpretation: Acute infusion of SNP resulted in greater glucose uptake relative to verapamil. NO may
\end{abstract}

D. C. Henstridge · B. A. Kingwell $(\bowtie) \cdot$ M. F. Formosa

B. G. Drew · S. J. Duffy

Alfred \& Baker Medical Unit, Baker Heart Research Institute,

St Kilda Rd Central,

P.O. Box 6492 8008, Melbourne, VIC, Australia

e-mail: b.kingwell@alfred.org.au

Tel.: +613-9276-3261

Fax: $+613-9276-2495$

D. C. Henstridge $\cdot$ B. G. Drew

Department of Medicine, Alfred Hospital, Monash University,

Melbourne, VIC, Australia

G. K. McConell

Department of Physiology, Melbourne University,

Parkville, VIC, Australia therefore be an important mediator of peripheral glucose disposal and a potential therapeutic target in patients with type 2 diabetes.

Keywords Contraction - Glucose - Leg blood flow · Nitric oxide Type 2 diabetes

Abbreviations AMPK: AMP-activated protein kinase A-V: arterio-venous - nNOS: neuronal NOS $\cdot$ NO: nitric oxide $\cdot$ NOS: NO synthase $\cdot$ SNP: sodium nitroprusside

\section{Introduction}

Nitric oxide (NO) has been implicated as an important signalling molecule in the contraction-mediated glucose uptake pathway and may represent a novel strategy for blood glucose control. Skeletal muscle is the major site of glucose disposal in humans, with insulin and muscular contraction being the two major stimuli for glucose uptake. Both mechanisms increase glucose uptake via translocation of solute carrier family 2 (facilitated glucose transporter), member 4 (SLC2A4, formerly known as GLUT4), from the cytosol of the muscle cell to the plasma membrane and ttubules. Patients with type 2 diabetes [1] and insulin-resistant obese Zucker rats [2] have impaired insulin-stimulated SLC2A4 translocation; however, exercise-stimulated SLC2 A4 translocation is normal [3,4]. The signalling pathways through which these distinct mechanisms operate differ [5]. While the insulin pathway involves insulin binding to its receptor inducing tyrosine kinase activity, phosphorylation of insulin receptor substrate proteins with subsequent activation of phosphatidylinositol-3-kinase [6], the contraction pathway, is independent of these steps [7-9]. A number of molecules including calcium $[5,10]$, protein kinase $\mathrm{C}$ [5], AMP-activated protein kinase (AMPK) [11], bradykinin [12] and NO [13] have been implicated in contractionmediated glucose uptake.

$\mathrm{NO}$ is produced from L-arginine by NO synthase (NOS), and neuronal NOS (nNOS) is the main NOS isoform expressed in human skeletal muscle fibres [14]. Electrical 
stimulation, eliciting muscle contraction causes release of NO [15]. Animal studies have demonstrated that NO donor drugs such as sodium nitroprusside (SNP) increase glucose transport in skeletal muscle [13, 16-19]. SNP also increases SLC2A4 translocation in isolated rat skeletal muscle preparations [16]. Of clinical relevance is the observation that NOS inhibition during cycle exercise reduced leg glucose uptake by $48 \%$ in young, healthy humans independently of effects on leg blood flow or plasma insulin levels [20]. In patients with type 2 diabetes NOS inhibition during cycle exercise had a more pronounced effect, reducing leg glucose uptake by $75 \%$ [21]. This suggests that patients with type 2 diabetes may compensate for impaired insulin action through augmented NO-mediated glucose uptake [21]. Whether exogenously delivered NO can improve glucose uptake at rest in patients with type 2 diabetes is unknown. The present study therefore investigated the effect of intra-femoral infusion of the NO donor SNP on leg glucose uptake at rest in patients with type 2 diabetes, and compared this with the effects of a calcium antagonist (verapamil) infusion titrated to produce matching leg blood flow responses.

\section{Subjects and methods}

\section{Participants}

Fifteen Caucasian males with type 2 diabetes (fasting plasma glucose $>7 \mathrm{mmol} / \mathrm{l}$ and/or plasma glucose levels of $>11.1 \mathrm{mmol} / 1$ after a $75 \mathrm{~g}$ oral glucose load [22], age range 47-59 years, Table 1) participated. All volunteers were non-smokers and free of overt coronary disease (based on lack of symptoms and a normal 12-lead ECG). Twelve participants were controlled by lifestyle modification only and three were treated with gliclazide (half-life 10-12 h). Patients medicated for other conditions were excluded. All were normally active but were not specifically exercise trained. The protocol was approved by the Alfred Hospital Ethics Committee, and conducted in accordance with the Declaration of Helsinki of the World Medical Association.

Table 1 Participant characteristics (means \pm SEM)

\begin{tabular}{lc}
\hline Age (years) & $54 \pm 1$ \\
Weight $(\mathrm{kg})$ & $90.9 \pm 3.9$ \\
BMI $\left(\mathrm{kg} / \mathrm{m}^{2}\right)$ & $28.7 \pm 0.9$ \\
Systolic blood pressure $(\mathrm{mmHg})$ & $133 \pm 4$ \\
Diastolic blood pressure $(\mathrm{mmHg})$ & $82 \pm 2$ \\
Fasting blood glucose $(\mathrm{mmol} / \mathrm{l})$ & $9.06 \pm 0.81$ \\
Fasting plasma insulin $(\mathrm{pmol} / \mathrm{l})$ & $151 \pm 42$ \\
$\mathrm{HbA}_{1} \mathrm{c}(\%)$ & $7.54 \pm 0.53$ \\
Total cholesterol $(\mathrm{mmol} / \mathrm{l})$ & $5.00 \pm 0.25$ \\
HDL-cholesterol $(\mathrm{mmol} / \mathrm{l})$ & $1.00 \pm 0.05$ \\
LDL-cholesterol $(\mathrm{mmol} / \mathrm{l})$ & $2.96 \pm 0.17$ \\
Triglycerides $(\mathrm{mmol} / \mathrm{l})$ & $2.29 \pm 0.47$ \\
\hline
\end{tabular}

Blood pressure was measured by automated oscillometric brachial sphygmomanometry (Dinamap, 1846 SXP; Critikon, Tampa, FL, USA) at the initial screening visit
All volunteers provided written informed consent prior to participation.

\section{Experimental design}

On the experimental day, participants received a dosegraded intra-femoral artery infusion of both SNP and verapamil (control) over $30 \mathrm{~min}$ in a randomised order. The two infusions were separated by a $90 \mathrm{~min}$ wash-out period. The dose of SNP was increased at $10 \mathrm{~min}$ intervals from 0.1 to 0.3 to $0.6 \mu \mathrm{g} \mathrm{kg}^{-1} \mathrm{~min}^{-1}$ and verapamil from 1 to 3 to $6 \mu \mathrm{g} \mathrm{kg}^{-1} \mathrm{~min}^{-1}$. Dose incrementation was necessary to monitor blood pressure responses and avoid hypotensive episodes owing to systemic effects. Leg blood flow was measured and arterial and venous femoral blood samples were obtained prior to infusion and during the final $2 \mathrm{~min}$ of both 30 min drug infusions.

\section{Experimental procedures}

Participants were requested to refrain from exercise, alcohol, caffeine and diabetic medication (if any) for the $24 \mathrm{~h}$ period prior to the experimental trial. After an overnight fast, participants attended the Alfred Hospital at 0800 hours. To avoid hypoglycaemia, 90 min prior to each drug infusion patients consumed a standardised light, lowglycaemic-index snack. Teflon catheters were placed in the right femoral artery (3.0 F; Cook Australia, Brisbane, Australia) and right femoral vein (4.0 F; Cook Australia) under local anaesthetic (1\% lignocaine; Astra, Sydney, Australia) using strict aseptic conditions. The artery was cannulated $\sim 2 \mathrm{~cm}$ and the vein $\sim 4 \mathrm{~cm}$ below the inguinal ligament, and the catheters advanced $\sim 10 \mathrm{~cm}$ and $\sim 4 \mathrm{~cm}$ centrally, respectively. A thermistor probe (Edslab 94-030$2.5 \mathrm{~F}$; Baxter Healthcare, Irvine, CA, USA) was inserted through the venous catheter and advanced $\sim 8 \mathrm{~cm}$ beyond the catheter tip $[20,21]$. The catheters were used for simultaneous arterial and venous blood sampling, arterial blood pressure measurement, arterial drug infusions and for venous blood flow measurement. Chest electrodes were positioned for monitoring of heart rate by ECG. Blood pressure, blood temperature and infusate temperature were digitised at $500 \mathrm{~Hz}$ using a 486/50 IBM-compatible PC and a data-acquisition system incorporating a 12-bit analogueto-digital converter (McPherson Scientific, Melbourne, Australia). Systolic, diastolic and mean blood pressure and heart rate were derived on a beat-to-beat basis from the blood pressure signal using a variable threshold peakdetection technique. Electronic callipers were used to average these signals over appropriate time intervals.

\section{Drug infusions}

SNP is a direct-acting smooth muscle relaxant which causes consequent dilation of the peripheral arterial and venous systems. Verapamil is a calcium ion influx inhibitor 
(slow channel blocker or calcium ion antagonist) which modulates the influx of ionic calcium across the cell membrane of the vascular smooth muscle as well as in contractile and conductile myocardial cells. Its action in vascular smooth muscle causes relaxation and dilation resulting in a reduction in peripheral vascular resistance. SNP (Mayne Pharma, Mulgrave, Australia) and verapamil (Abbott Australasia, Kurnell, Australia) were diluted in $0.9 \% \mathrm{NaCl}$ and infused at $2 \mathrm{ml} / \mathrm{min}$.

\section{Leg blood flow}

Right femoral venous blood flow was measured by constant-rate infusion of cold saline according to the thermodilution principle before and after each drug infusion $[20,21,23]$. Cold saline was drawn from a reservoir, and then immediately infused through the femoral venous catheter $\left(5-8^{\circ} \mathrm{C}\right)$ using an Angiomat 3000 Injector (LeibelFlarsheim, Sybron Corporation, Cincinnati, OH, USA). The cold saline infusion rate was titrated to produce a $\sim 0.9-1.2^{\circ} \mathrm{C}$ decrease in blood temperature [23]. Leg blood flow was generally measured at an infusion rate of $0.7 \mathrm{ml} / \mathrm{s}$ for $20 \mathrm{~s}$. However, in heavier participants it was necessary to increase this rate to a maximum of $1.0 \mathrm{ml} / \mathrm{s}$ to produce the necessary blood temperature decrement.

Blood sampling and analysis

Blood for biochemical analysis was immediately placed on ice, then centrifuged at $1,500 \mathrm{~g}$ with the plasma frozen at $-80^{\circ} \mathrm{C}$ for later analysis. Plasma total cholesterol (intraand inter-assay precision $\leq 2.5$ and $2.7 \%$, respectively), LDL-cholesterol (intra- and inter-assay precision $\leq 4.9$ and $4.3 \%$, respectively), HDL-cholesterol (intra- and interassay precision $\leq 3.4$ and $4.5 \%$, respectively) and triglycerides (intra- and inter-assay precision $\leq 1.6$ and $2.3 \%$, respectively) were measured with an enzyme-based assay using a Cholestech L.D.X (Cholestech Corporation, Hayward, CA, USA). Glucose concentrations (triplicate) were measured using enzymatic, spectrophotometric techniques with a Cobas-BIO centrifugal analyser (Roche Diagnostic Systems, Basel, Switzerland) (intra- and inter-assay precision $\leq 1.0$ and $1.7 \%$, respectively). Arterial plasma insulin concentration was measured in duplicate by RIA (Linco Research, St Charles, MO, USA) (intra- and interassay precision $\leq 4.4$ and $6 \%$, respectively). The product of arterio-venous (A-V) glucose concentration difference and leg blood flow was used to calculate whole leg glucose uptake.

\section{Statistics}

Statistical analyses were performed using SPSS software (version 12.0). All results are expressed as means \pm SEM. Two-way ANOVA for repeated measures was used to compare the change in all parameters between interven- tions with drug order as a between-participants variable. There was no effect of order of intervention on any parameter. The null hypothesis was rejected at $p<0.05$.

\section{Results}

\section{Participant characteristics}

Participant characteristics at the screening visit are presented in Table 1. Eight participants were overweight (BMI $>25 \mathrm{~kg} / \mathrm{m}^{2}$ ) and five were obese (BMI $>30 \mathrm{~kg} / \mathrm{m}^{2}$; Table 1). Seven participants had either systolic blood pressure $\geq 140 \mathrm{mmHg}$ or diastolic blood pressure $\geq 90 \mathrm{mmHg}$. Total plasma cholesterol was only elevated above $5.5 \mathrm{mmol} / \mathrm{l}$ in one patient but nine patients had an HDL level of $<1 \mathrm{mmol} / 1$. No participant had $\mathrm{HbA}_{1} \mathrm{c}$ values $>11 \%$, indicating reasonable glycaemic control (Table 1).

\section{Blood pressure and leg blood flow}

At baseline, neither blood pressure nor heart rate differed between the two drug interventions. Both systolic and
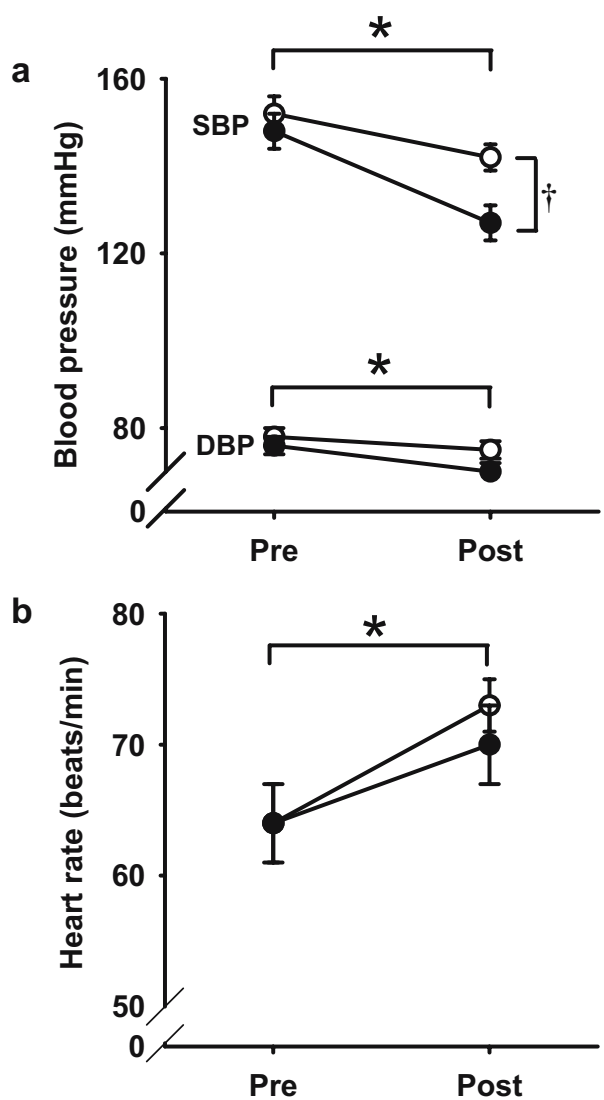

Fig. 1 Average systolic blood pressure (SBP), diastolic blood pressure (DBP) (a) and heart rate (b) before (Pre) and during-SNP (black circles) and verapamil (white circles) infusions (Post). Data are means \pm SEM. ${ }^{*} p \leq 0.001$ for decline over time with infusion; $t p<0.05$ for difference between SNP infusion and verapamil infusion 
diastolic blood pressure were significantly reduced by both drugs although the decline in systolic blood pressure was greater for SNP (Fig. 1a). The greater decline in systolic blood pressure with SNP may relate to its venodilatory effects, which would probably reduce preload and thus cardiac output. There was a baroreflex-mediated increase in heart rate, which was similar for both drugs (Fig. 1b).

Leg blood flow did not differ prior to either drug infusion (SNP $0.34 \pm 0.03$, verapamil $0.34 \pm 0.031 / \mathrm{min}$; $p=0.92)$ and increased significantly $(p<0.001)$ and to a similar extent during both the SNP and verapamil infusions

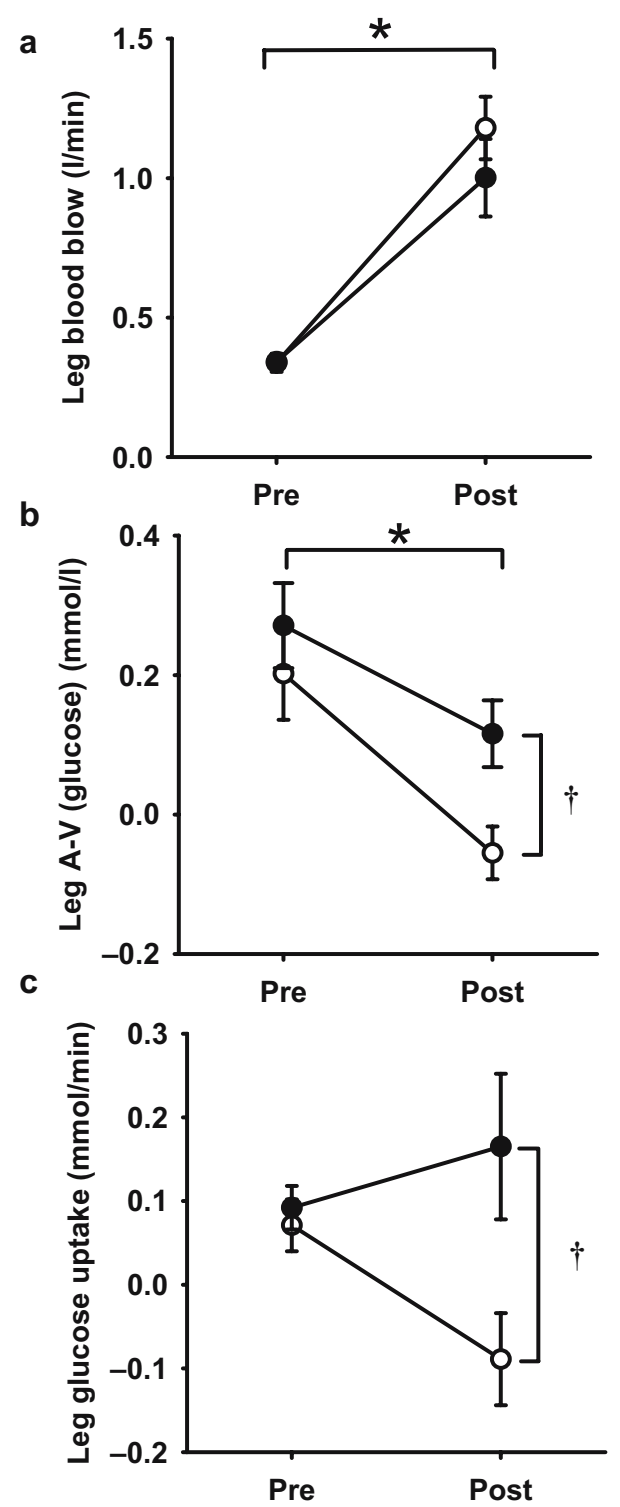

Fig. 2 Leg blood flow (a), leg A-V glucose concentration (b) and leg glucose uptake (c) before (Pre) and during the final 2 min of SNP (black circles) and verapamil (white circles) infusions (Post). Data are means \pm SEM. ${ }^{*} p<0.05$ for change in A-V glucose over time with infusion; $p<0.001$ for change in leg blood flow over time with infusion; $\uparrow p=0.03$ for difference between SNP and verapamil infusions
(SNP to $1.00 \pm 0.14$; verapamil to $1.18 \pm 0.111 / \mathrm{min} ; p=0.50$; Fig. 2a). Thus, despite slight differences between drugs with regard to blood pressure, leg blood flow and therefore glucose delivery to the leg did not differ significantly between drugs.

\section{Leg glucose uptake}

As expected, A-V glucose concentration was positive at baseline, indicating net uptake of glucose by the leg. This parameter was not different between treatment groups at baseline. During the final 2 min of drug infusion, the A-V glucose concentration was higher with SNP than with verapamil (SNP 0.12 \pm 0.05 , verapamil $-0.06 \pm 0.04 \mathrm{mmol} / \mathrm{l}$; $p=0.03$; Fig. 2b). Total glucose uptake (product of leg blood flow and $\mathrm{A}-\mathrm{V}$ glucose concentration) prior to infusion was the same for both treatment groups (SNP 0.09 \pm 0.03 , verapamil $0.07 \pm 0.03 \mathrm{mmol} / \mathrm{l}$; Fig. 2c). During the final 2 min of drug infusion, leg glucose uptake was significantly greater with SNP compared with verapamil treatment (SNP $0.17 \pm 0.09$, verapamil $-0.09 \pm 0.06 \mathrm{mmol} / 1 ; p=0.03$; Fig. $2 \mathrm{c}$ ).

\section{Plasma insulin}

There was no difference in arterial plasma insulin concentrations before (SNP 148 \pm 40 , verapamil $159 \pm 43 \mathrm{pmol} / \mathrm{l}$; Fig. 3) or after either treatment (SNP $118 \pm 34$, verapamil $133 \pm 32 \mathrm{pmol} / 1 ; p=0.56$; Fig. 3 ). Insulin levels at the end of both infusions tended to be lower than pre-infusion values, although this was not significant $(p=0.34)$. While not significant, the tendency for insulin to decline with both treatments was probably due to the participants' fasting state. This would have minimised the effect of SNP on glucose uptake and contributed to the trend for a decline in glucose uptake during verapamil. In support of this contention, when glucose uptake at the end of the infusions was compared using the insulin values upon completion of the drug infusion as a covariate, the $p$ value for leg glucose uptake decreased from 0.03 to 0.01 .

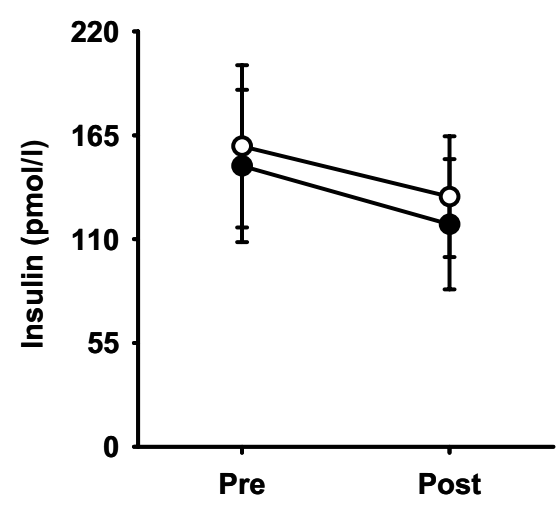

Fig. 3 Arterial plasma insulin concentration before (Pre) and during the final 2 min of SNP (black circles) and verapamil (white circles) infusions (Post). Data are means \pm SEM 


\section{Discussion}

The major finding of this study was that the NO donor SNP resulted in greater leg glucose uptake at rest in patients with type 2 diabetes mellitus compared with a verapamil infusion titrated to elicit a similar increase in leg blood flow. This was not an insulin-mediated effect since it occurred without a change in plasma insulin levels. The current study extends extensive animal literature directly implicating NO in skeletal muscle glucose uptake. It is also the first study to report a blood-flow-independent effect of exogenous NO on glucose uptake in humans. If substantiated, NO donors could form the basis of a novel therapeutic approach to blood glucose control.

SNP increases glucose transport in a number of cell culture models including human peripheral blood mononuclear cells [24], 3T3-L1 adipocytes [25], L929 fibroblasts [26], isolated rat cardiomyocytes [27] and human vascular smooth muscle cells [28]. SNP also increases glucose transport in isolated rat skeletal muscle preparations $[13,16-19]$. The fact that SNP is able to increase glucose uptake in both cell culture and isolated muscle preparations suggests that NO has a direct action on glucose transport via SLC2A4 translocation, in addition to increasing glucose delivery via effects on blood flow. In support of this hypothesis, SNP was recently shown to increase SLC2A4 translocation and glucose uptake in rat anterior and posterior left ventricular papillary muscles [29] and skeletal muscle [16]. While NO is an important metabolite of SNP [30], it is also possible that SNP exerts its actions via ferrocyanide [27]. However, SNP has effects on glucose uptake beyond those reported with ferrocyanide [27]. Furthermore, the NOS inhibition studies discussed below suggest that NO is indeed a mediator of glucose uptake in skeletal muscle.

Additional evidence for a role of NO in glucose transport is provided by NOS inhibition studies. Nitro-L-argininemethyl-ester added to the drinking water of SpragueDawley rats prior to a 45-min exhaustive treadmill run, reduced contraction-stimulated SLC2A4 translocation and glucose transport [31]. In humans, $N^{\mathrm{G}}$-monomethyl-L-arginine administered into the femoral artery during exercise reduced glucose uptake in healthy individuals [20] and to a greater extent in patients with type 2 diabetes [21]. This occurred in the absence of any change in total leg blood flow or insulin levels $[20,21]$. While the evidence for a role of NO in glucose uptake is overwhelming, the specific involvement of $\mathrm{NO}$ in contraction-mediated glucose uptake is not without controversy. Two NOS inhibition studies in rats have failed to show any effect on contraction-stimulated glucose uptake [16, 17], although both measured glucose uptake after completion of exercise or electrical stimulation, while the human studies displaying positive NOS inhibition results measured glucose uptake during exercise $[20,21]$.

Regardless of whether NO is part of the contractionmediated glucose uptake pathway, we have shown for the first time that an NO donor can stimulate glucose uptake in humans relative to a relevant blood flow control (verap- amil). Since blood flow is a key determinant of glucose uptake and NO donors also increase blood flow, it was important that this effect be measured relative to a control drug which increased blood flow to a similar extent. Both drugs reduced the $\mathrm{A}-\mathrm{V}$ glucose concentration gradient but this parameter was $0.10 \mathrm{mmol} / \mathrm{l}$ (Fig. 2b) higher during SNP than during verapamil. When multiplied by leg blood flow, leg glucose uptake was $0.26 \mathrm{mmol} / \mathrm{min}$ greater for SNP than for verapamil (Fig. 2c). If it is assumed that one leg corresponds to $\sim 30 \%$ of total body skeletal muscle mass [32], then whole body skeletal muscle glucose uptake at this rate would correspond to $137 \mathrm{~g}$ (seven tablespoons) of glucose per day compared with $77 \mathrm{~g}$ (four tablespoons) at basal levels. Furthermore, it is likely that NO would also stimulate glucose uptake in other tissues including cardiac muscle [27, 29] and adipose tissue [25]. Thus while the dose of NO used in this acute study could not be maintained chronically, the results demonstrate that in principle, NO donors could potentially assist in improving glycaemic control in patients with glucose intolerance and type 2 diabetes.

We have previously reported that mean glucose uptake after $25 \mathrm{~min}$ of cycling was $0.76 \mathrm{mmol} / \mathrm{min}$ [21]. This corresponds to $28 \mathrm{~g}$ of glucose during a 1-h exercise bout. Thus, an NO donor at approximately one-fifth the potency of the current study, delivered over $24 \mathrm{~h}$, would be expected to have effects equivalent to the known beneficial effects of a brief period of exercise on glucose uptake.

Interestingly, leg glucose uptake tended to decline with verapamil infusion. Verapamil is widely prescribed and is not known to have a significant effect on glucose metabolism at standard clinical doses [33]. No changes in insulinstimulated glucose uptake or glucose-stimulated insulin secretion were observed in patients with essential hypertension treated with $240 \mathrm{mg}$ verapamil twice daily for 20 weeks [34]. In an animal model of insulin resistance, the obese Zucker ( $f a / f a$ ) rat, oral administration of verapamil did not alter insulin-stimulated 2-deoxyglucose uptake in muscle [35]. Since muscle is not gluconeogenic, the negative glucose uptake observed with verapamil infusion indicates that at high blood flow, the small magnitude of the A-V glucose difference was below the sensitivity threshold for detection. If verapamil does not affect glucose uptake directly, then the trend for a reduction in glucose uptake during the verapamil infusion may reflect the fact that insulin trended to decline (Fig. 3) during the time-course of the study. The greater significance (as indicated by a reduction in the $p$ value) for the difference in glucose uptake between SNP and verapamil after inclusion of insulin as a covariate suggests that the trend for a reduction in insulin may have minimised the effects of SNP on glucose uptake.

Organic nitrates are routinely used in clinical practice for the treatment of angina pectoris. While there have not been any reports of hypoglycaemia with nitrate use, there has been no systematic study of the effects of chronic organic nitrate therapy on glucose metabolism. Many patients treated with nitrates frequently receive concomitant therapy with drugs such as beta-blockers or diuretics, which may adversely affect glucose metabolism and thus may 
mask any effect of nitrates on glucose uptake. Furthermore, there has been some controversy as to whether many organic nitrates are, in fact, true NO donors [36].

\section{Mechanisms}

The findings of the current study are in agreement with a small previous study which reported that SNP increased glucose uptake in healthy individuals but did not include an intervention which controlled for elevation in blood flow [37]. Similarly, methacholine increased leg glucose uptake [38], but it was assumed that such effects were a consequence of NO-mediated endothelial-dependent vasodilation and increased glucose delivery. Consistent with animal data $[13,16-19,29]$ the current study suggests that SNP increased glucose uptake beyond the effects on blood flow via increasing translocation of the SLC2A4 glucose transporter.

Although the effects of SNP on glucose uptake were independent of changes in total leg blood flow, it is possible that shunting within the muscle occurred. Two separate circulations termed nutritive and non-nutritive have been proposed to exist within skeletal muscle [39]. Vessels in the nutritive pathway are in direct contact with skeletal muscle cells whereas the non-nutritive pathway acts as a functional shunt, preventing nutrient exchange between muscle cells and blood [40]. If SNP preferentially directed blood to nutritive vascular beds it is possible that glucose uptake could increase without any difference in total blood flow compared with verapamil. While SNP is not known to affect inter-organ blood flow [41], we cannot exclude this possibility. However, the animal evidence for a direct effect of $\mathrm{NO}$ on SLC2A4 translocation and glucose uptake is substantial.

\section{Signalling pathways}

It is likely that NO mediates its effects on glucose uptake at least partly via stimulation of soluble guanylate cyclase and production of cGMP. Both muscle contraction [42] and SNP [18, 42] increase cGMP formation. Furthermore pharmacological manipulation of both soluble guanylate cyclase and cGMP modulates the effect of SNP on glucose uptake [18, 43].

During exercise or electrical stimulation of rat skeletal muscle, AMPK increases SLC2A4 translocation [44] and glucose uptake $[11,45]$. It has been postulated that NO and AMPK are part of the same signalling pathway. During exercise, AMPK phosphorylates nNOS $\mu$ in human skeletal muscle [46-48], while in rat skeletal muscle glucose uptake stimulated by the AMP analogue, 5-aminoimidazole-4carboxamide ribonucleoside, which activates AMPK, can be blocked by an NOS inhibitor [49]. Further studies are required to clarify the relationship between NO and AMPK with regard to glucose uptake.

\section{Conclusion}

This is the first human study to provide evidence that the NO donor SNP stimulates glucose uptake relative to a drug inducing a similar blood flow response. NO may be an important mediator of peripheral glucose disposal and a potential therapeutic target in patients with type 2 diabetes. Studies utilising other NO donors will clarify the role of $\mathrm{NO}$ in mediating peripheral glucose uptake.

Acknowledgements The authors wish to thank Dr Barbora de Courten for reviewing the manuscript and Donna Vizi and Melanie Ralph for their expert nursing and technical assistance. This work was supported by a project grant from the National Health and Medical Research Council of Australia. B. A. Kingwell is a National Health and Medical Research Council of Australia Senior Research Fellow. S. J. Duffy is supported by a National Health and Medical Research Council of Australia Career Development Award.

\section{References}

1. Zierath JR, He L, Guma A, Odegoard Wahlstrom E, Klip A, Wallberg-Henriksson H (1996) Insulin action on glucose transport and plasma membrane GLUT4 content in skeletal muscle from patients with NIDDM. Diabetologia 39:1180-1189

2. King PA, Horton ED, Hirshman MF, Horton ES (1992) Insulin resistance in obese Zucker rat (fa/fa) skeletal muscle is associated with a failure of glucose transporter translocation. J Clin Invest 90:1568-1575

3. Kennedy JW, Hirshman MF, Gervino EV et al (1999) Acute exercise induces GLUT4 translocation in skeletal muscle of normal human subjects and subjects with type 2 diabetes. Diabetes 48:1192-1197

4. King PA, Betts JJ, Horton ED, Horton ES (1993) Exercise, unlike insulin, promotes glucose transporter translocation in obese Zucker rat muscle. Am J Physiol 265:R447-R452

5. Hayashi T, Wojtaszewski JF, Goodyear LJ (1997) Exercise regulation of glucose transport in skeletal muscle. Am J Physiol 273:E1039-E1051

6. Holman GD, Kasuga M (1997) From receptor to transporter: insulin signalling to glucose transport. Diabetologia 40:9911003

7. Lee AD, Hansen PA, Holloszy JO (1995) Wortmannin inhibits insulin-stimulated but not contraction-stimulated glucose transport activity in skeletal muscle. FEBS Lett 361:51-54

8. Lund S, Holman GD, Schmitz O, Pedersen O (1995) Contraction stimulates translocation of glucose transporter GLUT4 in skeletal muscle through a mechanism distinct from that of insulin. Proc Natl Acad Sci USA 92:5817-5821

9. Goodyear LJ, Giorgino F, Balon TW, Condorelli G, Smith RJ (1995) Effects of contractile activity on tyrosine phosphoproteins and PI 3-kinase activity in rat skeletal muscle. Am J Physiol 268: E987-E995

10. Holloszy JO (2003) A forty-year memoir of research on the regulation of glucose transport into muscle. Am J Physiol Endocrinol Metab 284:E453-E467

11. Hayashi T, Hirshman MF, Kurth EJ, Winder WW, Goodyear LJ (1998) Evidence for 5' AMP-activated protein kinase mediation of the effect of muscle contraction on glucose transport. Diabetes 47:1369-1373

12. Kishi K, Muromoto N, Nakaya Y et al (1998) Bradykinin directly triggers GLUT4 translocation via an insulin-independent pathway. Diabetes 47:550-558

13. Balon TW, Nadler JL (1997) Evidence that nitric oxide increases glucose transport in skeletal muscle. J Appl Physiol 82:359-363 
14. Frandsen U, Lopez-Figueroa M, Hellsten Y (1996) Localization of nitric oxide synthase in human skeletal muscle. Biochem Biophys Res Commun 227:88-93

15. Balon TW, Nadler JL (1994) Nitric oxide release is present from incubated skeletal muscle preparations. J Appl Physiol 77:2519-2521

16. Etgen GJ Jr, Fryburg DA, Gibbs EM (1997) Nitric oxide stimulates skeletal muscle glucose transport through a calcium/ contraction- and phosphatidylinositol-3-kinase-independent pathway. Diabetes 46:1915-1919

17. Higaki Y, Hirshman MF, Fujii N, Goodyear LJ (2001) Nitric oxide increases glucose uptake through a mechanism that is distinct from the insulin and contraction pathways in rat skeletal muscle. Diabetes 50:241-247

18. Young ME, Radda GK, Leighton B (1997) Nitric oxide stimulates glucose transport and metabolism in rat skeletal muscle in vitro. Biochem J 322:223-228

19. Kapur S, Bedard S, Marcotte B, Cote CH, Marette A (1997) Expression of nitric oxide synthase in skeletal muscle: a novel role for nitric oxide as a modulator of insulin action. Diabetes 46:1691-1700

20. Bradley SJ, Kingwell BA, McConell GK (1999) Nitric oxide synthase inhibition reduces leg glucose uptake but not blood flow during dynamic exercise in humans. Diabetes 48:18151821

21. Kingwell BA, Formosa M, Muhlmann M, Bradley SJ, McConell GK (2002) Nitric oxide synthase inhibition reduces glucose uptake during exercise in individuals with type 2 diabetes more than in control subjects. Diabetes 51:2572-2580

22. Report of the expert committee on the diagnosis and classification of diabetes mellitus. (2003) Diabetes Care 26 [Suppl 1]: S5-S20

23. Andersen P, Saltin B (1985) Maximal perfusion of skeletal muscle in man. J Physiol 366:233-249

24. Lander HM, Sehajpal P, Levine DM, Novogrodsky A (1993) Activation of human peripheral blood mononuclear cells by nitric oxide-generating compounds. J Immunol 150:1509-1516

25. Tanaka T, Nakatani K, Morioka K et al (2003) Nitric oxide stimulates glucose transport through insulin-independent GLUT4 translocation in 3T3-L1 adipocytes. Eur J Endocrinol 149:61-67

26. Van Dyke DA, Walters L, Frieswyk D, Kokmeyer D, Louters LL (2003) Acute effects of troglitazone and nitric oxide on glucose uptake in L929 fibroblast cells. Life Sci 72:2321-2327

27. Jensen J, Sharikabad MN, Ostbye KM, Melien O, Brors O (2003) Evidence that nitroprusside stimulates glucose uptake in isolated rat cardiomyocytes via mitogen-activated protein kinase. Arch Physiol Biochem 111:239-245

28. Bergandi L, Silvagno F, Russo I et al (2003) Insulin stimulates glucose transport via nitric oxide/cyclic GMP pathway in human vascular smooth muscle cells. Arterioscler Thromb Vasc Biol 23:2215-2221

29. Li J, Hu X, Selvakumar P et al (2004) Role of the nitric oxide pathway in AMPK-mediated glucose uptake and GLUT4 translocation in heart muscle. Am J Physiol Endocrinol Metab 287:E834-E841

30. Ignarro LJ, Napoli C, Loscalzo J (2002) Nitric oxide donors and cardiovascular agents modulating the bioactivity of nitric oxide. Circ Res 90:21-28

31. Roberts CK, Barnard RJ, Scheck SH, Balon TW (1997) Exercise-stimulated glucose transport in skeletal muscle is nitric oxide dependent. Am J Physiol 273:E220-E225
32. Fuller NJ, Laskey MA, Elia M (1992) Assessment of the composition of major body regions by dual-energy X-ray absorptiometry (DEXA), with special reference to limb muscle mass. Clin Physiol 12:253-266

33. Trost BN, Weidmann P (1987) Effects of calcium antagonists on glucose homeostasis and serum lipids in non-diabetic and diabetic subjects: a review. J Hypertens, Suppl 5:S81-S104

34. Berne C, Pollare T, Lithell H (1991) Effects of antihypertensive treatment on insulin sensitivity with special reference to ACE inhibitors. Diabetes Care 14 [Suppl 4]:39-47

35. Jacob S, Henriksen EJ, Fogt DL, Dietze GJ (1996) Effects of trandolapril and verapamil on glucose transport in insulinresistant rat skeletal muscle. Metabolism 45:535-541

36. Kleschyov AL, Oelze M, Daiber A et al. (2003) Does nitric oxide mediate the vasodilator activity of nitroglycerin? Circ Res 93:e104-e112

37. Durham WJ, Yeckel CW, Miller SL, Gore DC, Wolfe RR (2003) Exogenous nitric oxide increases basal leg glucose uptake in humans. Metabolism 52:662-665

38. Baron AD, Steinberg H, Brechtel G, Johnson A (1994) Skeletal muscle blood flow independently modulates insulin-mediated glucose uptake. Am J Physiol 266:E248-E253

39. Barlow TE, Haigh AL, Walder DN (1961) Evidence for two vascular pathways in skeletal muscle. Clin Sci 20:367-385

40. Clark AD, Youd JM, Rattigan S, Barrett EJ, Clark MG (2001) Heterogeneity of laser Doppler flowmetry in perfused muscle indicative of nutritive and nonnutritive flow. Am J Physiol Heart Circ Physiol 280:H1324-H1333

41. Oates JA \& Brown NJ (2001) Antihypertensive agents and the drug therapy of hypertension. In: Hardman JG, Limbird LE, Goodman AG (eds) Goodman \& Gilman's The pharmacological basis of therapeutics (10th edn). McGraw-Hill, New York, pp 889-890

42. Lau KS, Grange RW, Isotani E et al (2000) nNOS and eNOS modulate cGMP formation and vascular response in contracting fast-twitch skeletal muscle. Physiol Genomics 2:21-27

43. Young ME, Leighton B (1998) Evidence for altered sensitivity of the nitric oxide/cGMP signalling cascade in insulin-resistant skeletal muscle. Biochem J 329:73-79

44. Kurth-Kraczek EJ, Hirshman MF, Goodyear LJ, Winder WW (1999) 5' AMP-activated protein kinase activation causes GLUT4 translocation in skeletal muscle. Diabetes 48:16671671

45. Bergeron R, Russell RR 3rd, Young LH et al (1999) Effect of AMPK activation on muscle glucose metabolism in conscious rats. Am J Physiol 276:E938-E944

46. Chen ZP, McConell GK, Michell BJ, Snow RJ, Canny BJ, Kemp BE (2000) AMPK signaling in contracting human skeletal muscle: acetyl-CoA carboxylase and NO synthase phosphorylation. Am J Physiol Endocrinol Metab 279:E1202E1206

47. Chen ZP, Stephens TJ, Murthy S et al (2003) Effect of exercise intensity on skeletal muscle AMPK signaling in humans. Diabetes 52:2205-2212

48. Stephens TJ, Chen ZP, Canny BJ, Michell BJ, Kemp BE, McConell GK (2002) Progressive increase in human skeletal muscle AMPKalpha2 activity and ACC phosphorylation during exercise. Am J Physiol Endocrinol Metab 282:E688-E694

49. Fryer LG, Hajduch E, Rencurel F et al (2000) Activation of glucose transport by AMP-activated protein kinase via stimulation of nitric oxide synthase. Diabetes 49:1978-1985 